\title{
Efeitos do clima e sazonalidade nos atropelamentos de Rhinella Jimi, em duas rodovias do Agreste de Pernambuco
}

As mudanças climáticas podem gerar algumas transformações na biosfera como o aumento dos eventos extremos (secas e enchentes) e aumento das temperaturas. As estradas são ambientes de desenvolvimento econômico e estão vinculadas aos processos de projeção da interiorização de determinada região, com tais benefícios as estradas também causam alguns efeitos à biodiversidade, como a formação de subpopulações, processos de fragmentação dos ambientes, como também animais atropelados, que em alguns períodos do ano, algumas espécies são mais frequentemente observadas atropeladas que outras. Neste sentido, o intuito deste trabalho foi verificar a relação existente entre o clima e a frequência de atropelamentos da espécie Rhinella jimi em dois fragmentos de rodovias no Semiárido pernambucano. As coletas do material informacional biológico foram feitas a partir de observação de duas rodovias pernambucanas, a BR 232 e 423. Os dados de distribuição e sazonalidade foram comparados com o número de atropelamentos da espécie. Foram verificados alguns fatores relacionados ao crescimento de indivíduos atropelados depois do período chuvoso, além de uma relação de crescimento dos atropelamentos durante as chuvas, indicando que os atropelamentos estão vinculados às atividades metabólicas do animal e seu consequente desenvolvimento populacional depois dos períodos de chuva, uma vez que a característica de adaptabilidade dos anfíbios no semiárido é vinculada a sua maior atividade e rápida reprodução nos períodos chuvosos e redução metabólica nos períodos mais secos e escassos de alimento. Assim, as flutuações pluviométricas ao longo do ano, além de permitirem adaptabilidade aos organismos, possibilitam pontualmente o seu desenvolvimento populacional no ambiente.

\section{Effects of climate and seasonality on pedestrian accidents at Rhinella Jimi, on two highways in the Agreste region of Pernambuco}

\begin{abstract}
Climate change, is a set of factors that generate some changes in the biosphere, such as changes in rainfall regularities, rising temperatures and other consequences such as rising ocean levels. Roads are environments of economic development and are linked to the processes of projection of the interiorization of a certain region, with such benefit the roads also have some effects on biodiversity, such as the formation of subpopulations and the processes of fragmentation of the environment. With this, it is quite common to observe animals hit by road environments. Analyzing this fact, it can be verified that in some parts of the year, some species are more often observed trampled than others. In this sense, the purpose of this work was to verify the relationship between the weather and the frequency of pedestrians of the species Rhinella jimi in two fragments of highways in the semiarid Pernambuco. Some factors related to the growth of trampled individuals (adults) after the rainy season were verified, as well as a relation of growth of trampling during the rains, demonstrating an idea that the trampling is linked to the metabolic activities of the animal and its consequent population development after of rainfall periods, since the adaptability characteristic of amphibians in the semiarid region is related to their greater activity and rapid reproduction in rainy periods and metabolic reduction in drier and scarce periods of food. Thus, climate change, besides allowing adaptability to organisms, makes it possible, in time, to grow in the environment.
\end{abstract}

Keywords: Climatic change; Roadkill fauna; Ecology.

\section{José Cleiton Souza Tenório (iD}

Universidade Federal do Agreste de Pernambuco, Brasi http://lattes.cnpq.br/4605803522318090 http://orcid.org/0000-0002-0613-200X tenoriocleiton@gmail.com

Arthur Macário Lopes (id)

Universidade Federal Rural de Pernambuco, Brasil http://lattes.cnpq.br/0178845536422489 http://orcid.org/0000-0002-0581-5351 arthurmacario07@outlook.com

Dayara Claudia Souto Maior de Moraes Vilar (iD) Universidade Federal Rural de Pernambuco, Brasil http://lattes.cnpq.br/5539681623261959 http://orcid.org/0000-0002-0754-6677 dayaraclaudia@gmail.com

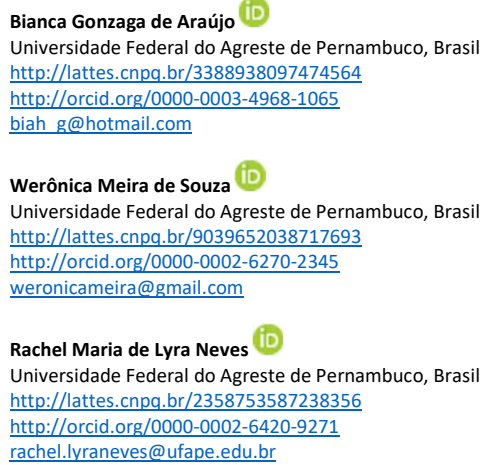

rachel.Iyraneves@ufape.edu.br

Wallace Rodrigues Telino Júnior (iD

Universidade Federal do Agreste de Pernambuco, Brasi http://lattes.cnpq.br/6964713876958962 http://orcid.org/0000-0002-5570-1993 wallace.telinojr@ufape.edu.br
Referencing this:

TENÓRIO, J. C. S.; LOPES, A. M.; VILAR, D. C. S. M. M.; ARAÚJO, B. G.; SOUZA, W. M.; NEVES, R. M. L.; TELINO JUNIOR, W. R.. Efeitos do clima e sazonalidade nos atropelamentos de Rhinella Jimi, em duas rodovias do Agreste de Pernambuco. Revista Ibero Americana de Ciências Ambientais, v.12, n.4, p.142-154, 2021. DOI: http://doi.org/10.6008/CBPC2179-6858.2021.004.0014 


\section{INTRODUÇÃO}

As mudanças climáticas trazem um futuro bastante incerto para a biodiversidade ainda existente no planeta. A herpetofauna em si sofre com redução de população, tamanho corporal e até mesmo mudanças na distribuição geográfica de espécies (BELLARD et al., 2012). Tais fatores levam a mudanças nas atividades reprodutivas e dieta, além do hábito de vida e do nicho ecológico em que as espécies são inseridas. É bem provável que as espécies da herpetofauna sejam, em sua maioria, vulneráveis aos efeitos climáticos por apresentarem ectotermia como característica primordial do grupo (BOHM et al., 2013).

Os efeitos das variabilidades climáticas e possivelmente das mudanças climáticas vêm afetando todo o planeta com desastres em grande escala, com alterações nos recursos hídricos e na agricultura no decorrer dos anos. Assis et al. (2015) afirmam que as mudanças do clima têm intensificado cada vez mais a problemática da escassez hídrica, sobretudo em áreas áridas e semiáridas do planeta, destacando o semiárido do Nordeste do Brasil, uma vez que apresenta uma grande tendência à aridização, acompanhada de diminuição da oferta hídrica em função da alteração nos padrões pluviométricos, com diminuição da frequência e intensidade das chuvas.

As alterações climáticas podem ser definidas como toda e qualquer alteração no clima ao longo de um determinado tempo. Tais alterações podem acontecer de forma natural ou como resultado da intervenção humana no ambiente, podendo gerar um efeito pontual ou global. Desta forma, as modificações nas temperaturas e precipitação resultam, além de modificações na biodiversidade mundial, também em relação de produção agrícola e pecuária pelo exacerbado estresse hídrico das culturas (CUNHA et al., 2015).

As discussões sobre os efeitos da climatologia no ambiente relacionados aos efeitos gerados pela atividade econômica estão muito vinculadas à emissão de gases do efeito estufa. Embora não se conheça totalmente os efeitos manifestados pelas alterações climáticas, já se observam eventos climáticos adversos relacionados ao aquecimento global, como mudanças nos regimes de precipitação e aumento dos níveis dos oceanos. Além do mais, tais efeitos podem agravar ainda mais os aspectos de vulnerabilidade socioeconômica das comunidades (DELAZERI et al., 2015).

Para o semiárido, as mudanças climáticas ainda são mais severas pelo fato de poder relaciona-las aos fatores de desertificação da região (ANGELOTTI et al., 2015) e, consequentemente, aos processos de vulnerabilidade social da população da região. O semiárido brasileiro é composto por áreas com precipitação média menor que $800 \mathrm{~mm}$ ao ano, com chuvas concentradas entre meados do segundo e terceiro trimestre do ano. A grande preocupação para com esta região está vinculada a seus períodos de seca gerados pelas temperaturas altas e o déficit hídrico da região (ANGELOTTI et al., 2015). Tais fatores naturais ligados ao clima, junto de seu processo de degradação e os fatores de aquecimento global gerados pelo crescimento econômico fazem com que se discuta uma ideia de processo de desertificação do semiárido e consequente êxodo da população que habita tal região (GUTIÉRREZ et al., 2014). 


\section{REVISÃO TEÓRICA}

\section{Ecologia de estradas}

O desenvolvimento econômico e o processo de interiorização em uma região estão diretamente ligados ao desenvolvimento do setor de transporte e, consequentemente, este crescimento está ligado ao processo de ampliação da infraestrutura de estradas e rodovias (BARAT, 1969; BERTUSSI et al., 2012). Junto ao desenvolvimento promovido pelas estradas, une-se a ideia de caracterizar a atividade antrópica como uma das que mais causam impacto e perda da biodiversidade em determinada região (BAGER et al., 2007).

A perda da biodiversidade promovida pelas rodovias, está vinculada à ideia de fragmentação dos ambientes naturais, causando nos indivíduos perda de ambiente natural para circulação, isolamento e formação de subpopulações (HADDAD et al., 2015). As alterações causadas em uma população de determinada espécie são variadas. Mudanças nos hábitos alimentares, teia trófica, reprodução ou até mesmo efeitos adversos pelo surgimento de uma borda no ambiente são os mais observados (TROMBULAK et al., 2000). Outro impacto causado pelas estradas está no quantitativo de espécimes atropelados diariamente (FORMAN et al., 2003), as espécies que resistem ao efeito de borda causado pelas estradas tendem a circular sobre os fragmentos, causando muitas vezes acidentes que reduzem ainda mais as populações remanescentes (FORNAN et al., 2003; HADDAD et al., 2015).

A diversidade genética das espécies é outro dos impactos atrelados à fragmentação dos ambientes por rodovias, já que as mesmas funcionam como barreiras para a circulação de espécies (CLARK et al., 2009), fazendo com que uma determinada população seja isolada em subpopulações e, consequentemente, reduzindo o fluxo gênico entre estas (FERREIRA NETO et al., 2017). O impacto ainda pode ser maior se vinculado à perda do valor hereditário de uma espécie quando atropelada.

Medidas para mitigar os atropelamentos e os efeitos da fragmentação causados pelas estradas são amplamente discutidos. $O$ uso de túneis e galerias de passagem de fauna, a instalação de placas em locais de maior fluxo de determinada espécie, ampliação do monitoramento de atropelamentos da fauna são algumas das medidas propostas (BAGER et al., 2013; RAMOS-ABRANTES et al., 2018).

\section{Anfíbios Anuros}

Os Anfíbios são constituídos por três ordens, sendo elas: Apoda, Urodela e Anura (HADDAD et al., 2013). Dentro dessas, a ordem mais abundante é a Anura constituída principalmente pelos sapos, rãs e pererecas. Possuem membros anteriores e posteriores além de uma fase larval aquática (HADDAD et al., 2013). Tal característica, unido à sensibilidade cutânea, faz com que esses organismos sejam bastante dependentes da água e de ambientes úmidos. Por estarem associados a ambientes úmidos, muitos desses indivíduos se tornam territorialistas e isolados de outras populações mesmo que próximas (SANTOS et al., 2014).

Possuem ampla distribuição reprodutiva e, desta forma, existem um elevado número de trabalhos envolvendo reprodução e distribuição temporal de anuros (LIPINSKI et al., 2014; SANTOS et al., 2014). Uma 
característica muito comum dos anfíbios adaptados ao bioma caatinga é que os mesmos possuem hábitos fossoriais, sobrevivendo com pouca umidade e rápido processo de desenvolvimento do organismo jovem para adultos, garantindo uma maior resistência ao ambiente inserido (ANDRADE et al., 2009). No bioma Caatinga, as espécies de anfíbios anuros conseguem se destacar em meio à seca e à fragmentação dos ambientes, por este motivo conseguem estar sempre vinculadas a estudos de diversidade além de hábitos e estratégias de adaptação e desenvolvimento nesta região (OLIVEIRA et al., 2017).

A espécie Rhinella jimi (STEVAUX, 2002) pertence à família Bufonidae, tem distribuição original no Nordeste brasileiro, mas pode ser encontrada como espécie invasora em outras regiões (FROST, 2010). Tal espécie é bastante resistente em relação às demais por apresentar hábitos terrestres e pele rugosa. Desta forma está bem difundida no ambiente antropizado (PEREIRA, 2012).

Por possuir hábitos terrestres, $R$. jimi possui abundância em ambientes úmidos temporários sendo considerados comuns em regiões mais secas, porém dependente dá água para reprodução (VIEIRA et al., 2007). Normalmente a espécie é carnívora, se alimentando basicamente de pequenos artrópodes (OLIVEIRA et al., 2015). Quanto a regulação homeostática, tais indivíduos são pecilotérmicos, tendo suas funções termorreguladoras e hábitos básicos nas primeiras horas do período noturno (ABRANTES et al., 2011).

O objetivo deste trabalho é analisar a relação existente entre o clima e a frequência de atropelamentos da espécie Rhinella jimi em dois fragmentos de rodovias no Semiárido pernambucano.

\section{MATERIAIS E MÉTODOS}

\section{Área de estudo}

Os dados de indivíduos da espécie Rhinella jimi(sapo-cururu) foram coletados em dois trechos de rodovias Federais do Estado de Pernambuco (Figura 1), uma na BR 423 no trecho Garanhuns-Águas Belas e outra na BR 232 no trecho São Caetano-Arcoverde. Esses dois trechos de rodovias ligam o Agreste ao Sertão de Pernambuco, podendo ser observadas fitofisionomias diferentes das áreas.

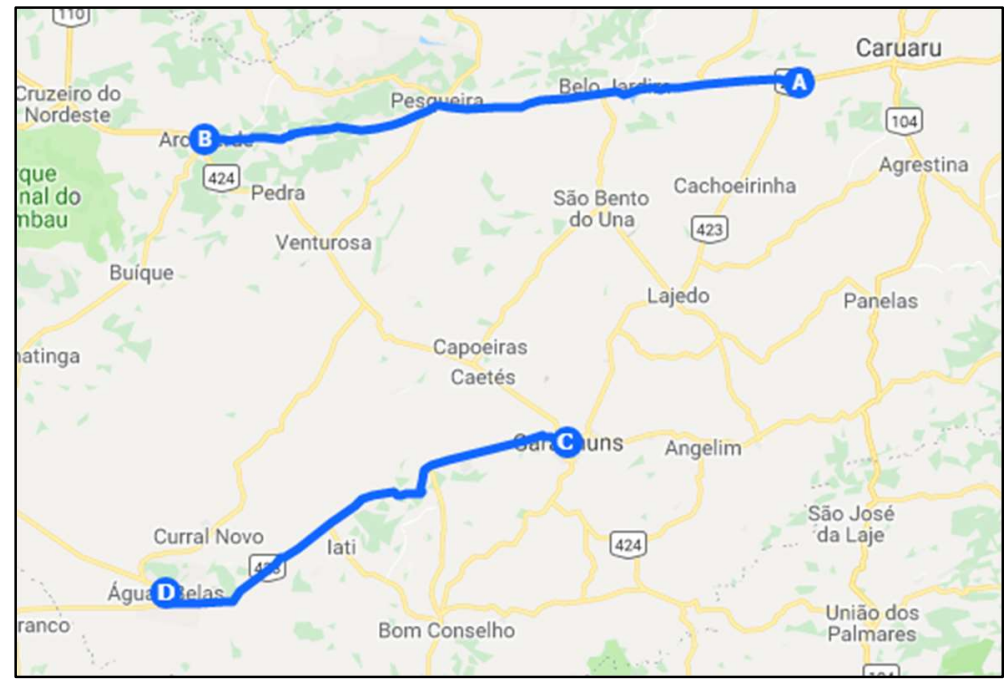

Figura 1: Trechos de rodovias onde foram coletados os espécimes de Rhinella jimi. A-B: BR232 no trecho São CaetanoArcoverde; C-D: BR432 no trecho Garanhuns-Águas Belas. 


\section{Monitoramento das rodovias}

As coletas de dados foram realizadas semanalmente utilizando um veículo oficial da Universidade Federal Rural de Pernambuco, Unidade Acadêmica de Garanhuns (atual Universidade Federal do Agreste de Pernambuco), com velocidade controlada de $50 \mathrm{~km} / \mathrm{h}$. Para o trecho da BR232 (Figura 1), o período de coleta foi entre os meses de agosto de 2016 e julho de 2017. Já para o trecho da BR423 (Figura 1), o período de coleta foi entre os meses de agosto de 2017 e julho de 2018.

\section{Coleta de dados}

Para a detecção do animal atropelado foi utilizado o método da observação visual a partir do veículo em deslocamento. $\mathrm{O}$ veículo transportou três pessoas, o motorista, o estudante ajudante e o estudante pesquisador.

Situado ao lado do motorista, o estudante pesquisador, ficou designado a localizar os atropelamentos na rodovia. Ao longo desse período, ocorreram eventuais substituições do motorista e do estudante ajudante, porém o estudante pesquisador se manteve o mesmo do início ao fim das coletas, garantindo a mesma capacidade de detecção visual ao longo do ano. Ao ser identificado um atropelamento pelo estudante pesquisador, o mesmo solicitou ao motorista que posicionasse o veículo no acostamento atrás do atropelamento para realização da identificação e coleta das informações. Em seguida era posicionado um cone de tráfego atrás do veículo, como medida indicativa para outros motoristas de ação na rodovia.

As informações coletadas foram a localização do atropelamento com o GPS-Garmin, latitude, longitude e altitude. Identificação da espécie atropelada e registro de imagens do indivíduo e do local do atropelamento. Para a identificação da espécie, foi utilizado as imagens coletadas do atropelamento e em alguns casos foi necessário, a coleta da carcaça ou de partes e o seu transporte para o Laboratório de necropsia do setor de Medicina Veterinária, fazendo a identificação final. Foram registradas quatro imagens do local do atropelamento o que possibilitou uma visualização de $360^{\circ}$, permitindo a identificação das características do local do atropelamento. Como forma de evitar a contagem consecutiva de um mesmo o animal ao longo das semanas, as carcaças foram removidas da rodovia com um auxílio de uma espátula adaptada.

O banco de dados foi construído com base nas informações coletadas, cada dado de indivíduo atropelado foi armazenado com as informações do local do atropelamento, localização e os registros fotográficos. O que possibilitou fazer um bom relacionamento do atropelamento com as características locais.

Os dados de precipitação pluviométrica para os mesmos períodos foram obtidos por meio da Agência Pernambucana de Água e Clima (APAC) para a região onde se concentrou maior número de espécimes da espécie Rhinella jimi. 


\section{RESULTADOS E DISCUSSÃO}

As médias de precipitação para o semiárido brasileiro são de 650mm segundo Marengo et al. (2016). Levando em consideração tal informação, os municípios de Pesqueira e Águas Belas, que possuem localização geográfica no Sertão e no Agreste Meridional de Pernambuco, respectivamente, possuem médias climatológicas de precipitação de 616,8 mm no município de Pesqueira (Figura 2) e 600,2 em Águas Belas (Figura 3) estando dentro da média de precipitação anual de chuvas para a região.

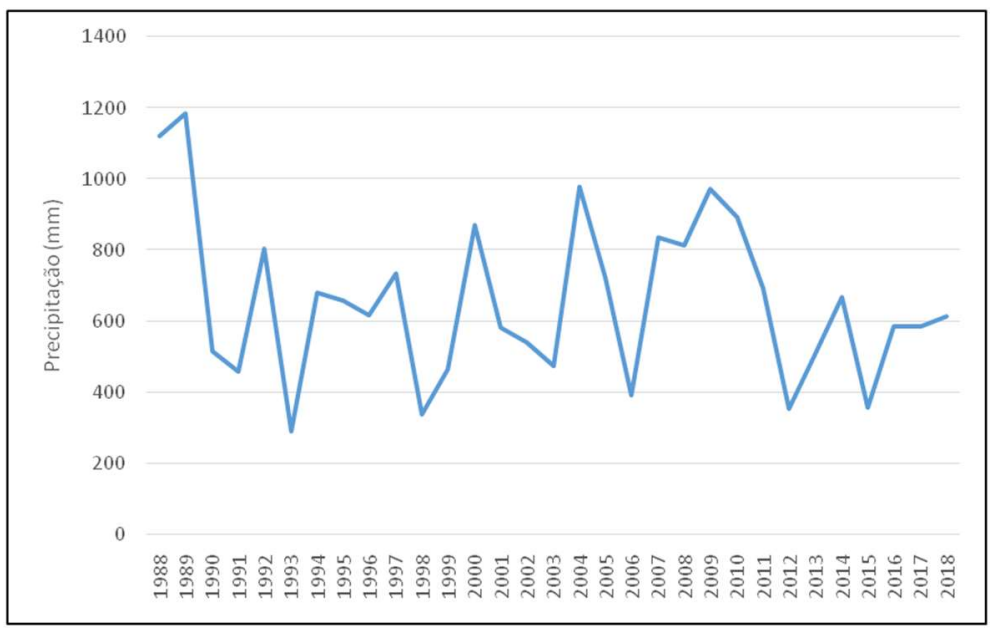

Figura 2: Climatologia de precipitação do município de Pesqueira, Pernambuco.

Tal região sempre foi demarcada por escassez de chuvas, além de um potencial estresse hídrico, mostrando anos com precipitações inferiores de $400 \mathrm{~mm}$ como está representado nas figuras 2 e 3 . Vale salientar que a região passou por um período de secas intensas no ano de 1998 e mais recente entre os anos de 2012 até 2015 (MARENGO et al., 2016).

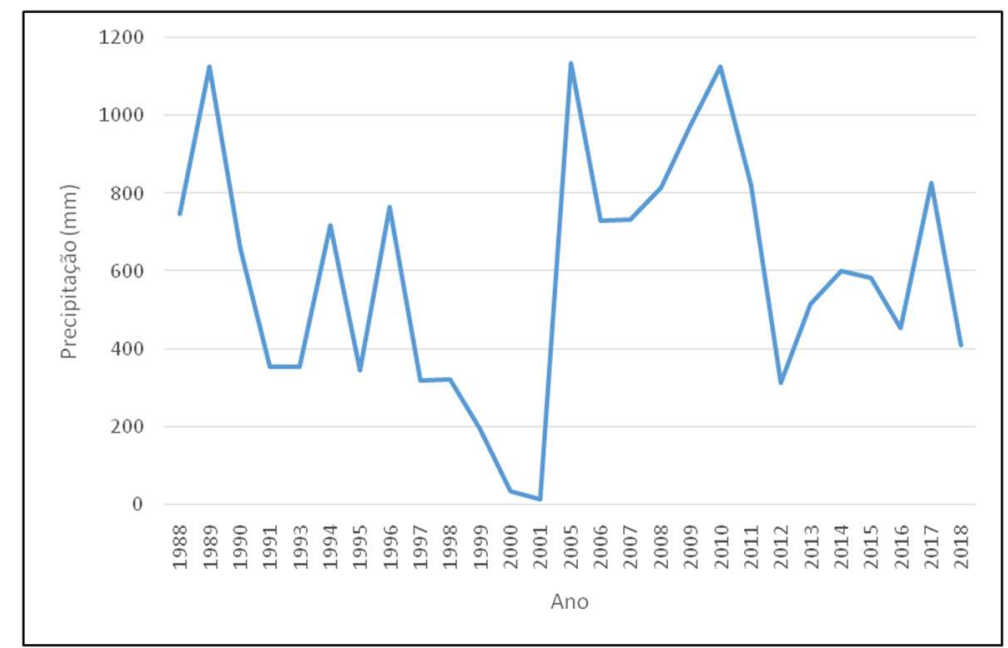

Figura 3: Climatologia de precipitação do município de Águas Belas, Pernambuco.

Apesar das secas serem um fenômeno natural, geram mudanças na estrutura hidrometeorológica, além de estresse hídrico na vegetação e aumentam os riscos de vulnerabilidade social das populações naturais inseridas neste contexto (EAKIN et al., 2014). As projeções futuras, em relação à escassez dos recursos hídricos na região semiárida brasileira, são de provável continuação ou intensificação (MARENGO et al., 2016), o que pode alcançar um prejuízo intenso para a população inserida nesta Região. 
As chuvas no Semiárido brasileiro se concentram basicamente entre os meses de abril e julho, e essa característica de não uniformidade faz com que grande parte do ano sofra com um período de seca, mesmo que o ano tenha um bom período anual de precipitação. Este fato pode ser observado nas médias de climatológicas mensais dos municípios de Pesqueira e Águas Belas (Figura 4).

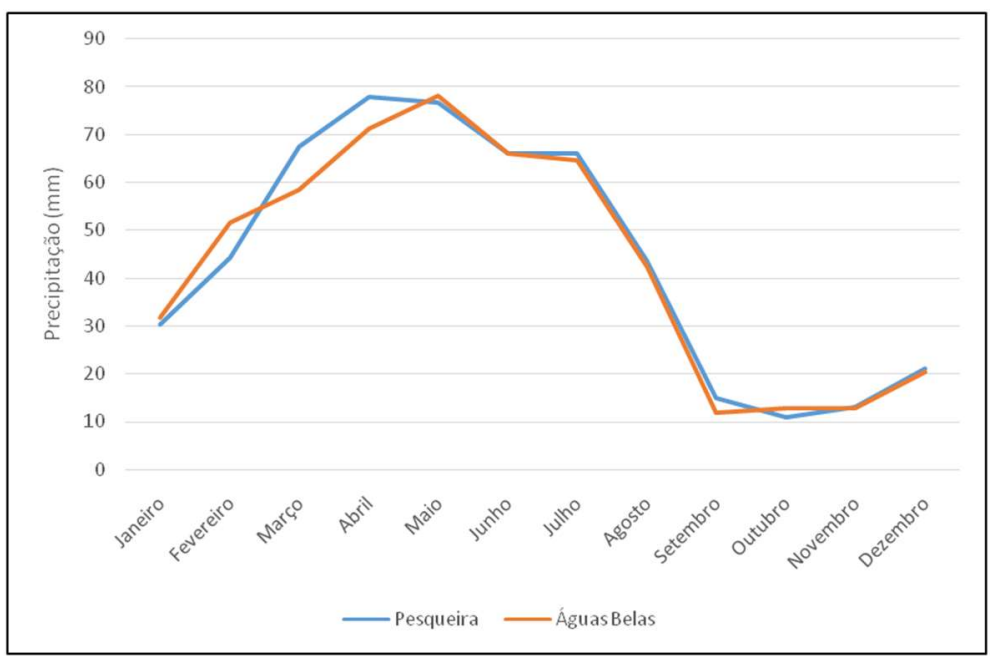

Figura 4: Climatologia de precipitação mensal do município de Pesqueira e Águas Belas, Pernambuco.

Pelos dados pluviométricos das duas áreas, percebe-se um padrão de precipitação mensal, em que os meses mais chuvosos apresentam uma média de precipitação de aproximadamente $85 \mathrm{~mm}$ e nos meses mais secos uma média de $10 \mathrm{~mm}$. Este fator, demonstra a irregularidade na distribuição das chuvas nos dois municípios que podem representar boa parte do que acontece na região semiárida. Essa irregularidade na distribuição gera fatores de adaptabilidade à biodiversidade inserida nesta região. Na vegetação, por exemplo, a maioria das espécies se apresenta no estado arbustivo ou de árvores baixas, o que condiz com o tipo de solo raso existente no ambiente. Ainda são encontradas neste ambiente plantas com elevado grau de suculência, como é o caso das cactáceas (ANDRADE et al., 2012; PRADO, 2003; ALVES, 2007). Para a herpetofauna, durante os períodos de estiagem, a redução no metabolismo é estrategicamente proveitosa (GUEDES et al., 2012), dessa forma, a Caatinga é considerada um bioma bastante rico em diversidade da herpetofauna, tanto de répteis quanto dos anfíbios anuros e outras espécies da fauna e flora, sendo um ambiente promissor ao desenvolvimento de pesquisa em diversas áreas.

Nos períodos mais chuvosos, as espécies tendem a obter com maior facilidade alimentos, o que fazem com que aumentem o seu potencial metabólico além de ser um período importante para o período reprodutivo de muitas espécies, como as de anfíbios, já que nestes períodos mais chuvosos ocorrem o acumulo de água (ANDRADE et al., 2012).

Em consequência das atividades metabólicas das espécies é muito comum, em determinadas épocas do ano, existir uma frequência maior de determinadas espécies. Seja por estarem em período reprodutivo ou pelo motivo de aumento da população em determinada região pontual por eventuais motivos, como chuvas, maior oferta de alimentos ou até mesmo redução do habitat natural daquela espécie (BAGER et al., 2013; RAMOS-ABRANTES et al., 2018).

Foram coletados 168 espécimes de R. jimi no trecho da BR423 e 68 espécimes no trecho da BR232 
distribuídos entre os meses de agosto de 2016 a julho de 2018. A frequência de ocorrência dos espécimes está distribuída na tabela 1.

Tabela 1: Frequência de ocorrência mensal da espécie Rhinella jimi nos trechos das rodovias federais BR423 e BR232.

\begin{tabular}{|c|c|c|}
\hline \multirow{12}{*}{ BR232 } & Agosto/2016 & 0 \\
\hline & Setembro/2016 & 3 \\
\hline & Outubro/2016 & 0 \\
\hline & Novembro/2016 & 1 \\
\hline & Dezembro/2016 & 1 \\
\hline & Janeiro/2017 & 0 \\
\hline & Fevereiro/2017 & 0 \\
\hline & Março/2017 & 9 \\
\hline & Abril/2017 & 26 \\
\hline & Maio/2017 & 25 \\
\hline & Junho/2017 & 2 \\
\hline & Julho/2017 & 0 \\
\hline \multirow{12}{*}{ BR423 } & Agosto/2017 & 6 \\
\hline & Setembro/2017 & 2 \\
\hline & Outubro/2017 & 0 \\
\hline & Novembro/2017 & 1 \\
\hline & Dezembro/2017 & 82 \\
\hline & Janeiro/2018 & 30 \\
\hline & Fevereiro/2018 & 5 \\
\hline & Março/2018 & 15 \\
\hline & Abril/2018 & 13 \\
\hline & Maio/2018 & 1 \\
\hline & Junho/2018 & 2 \\
\hline & Julho/2018 & 2 \\
\hline
\end{tabular}

A partir dos dados de distribuição dos indivíduos coletados mensalmente, pode-se observar que em alguns meses a frequência de atropelamentos de Rhinella jimi é maior que em outros.

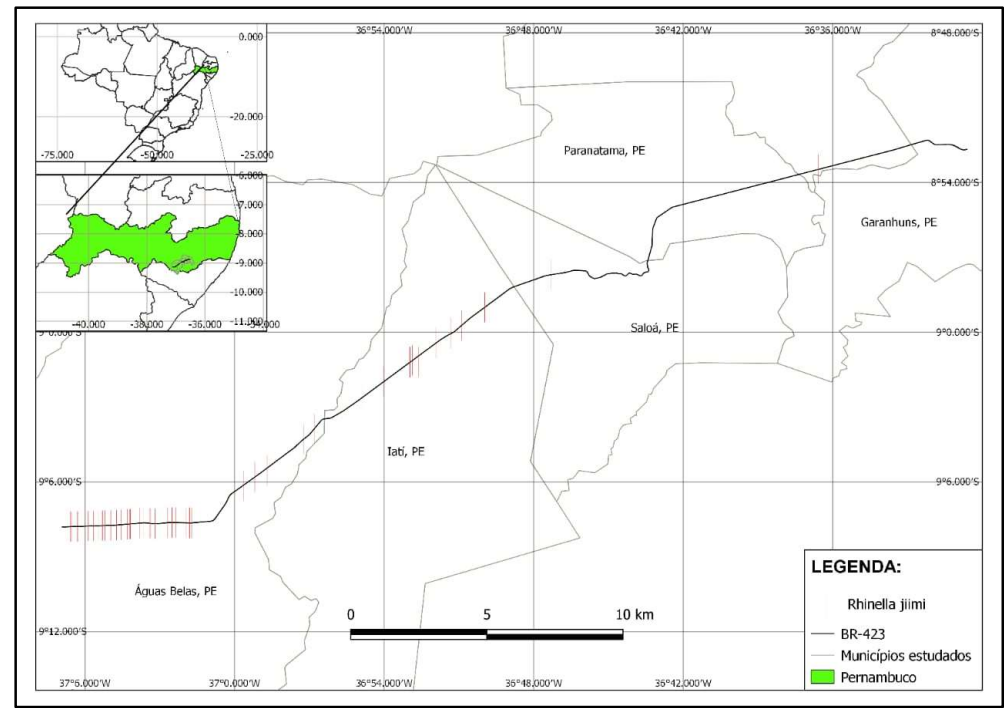

Figura 5: Distribuição espacial de indivíduos da espécie Rhinella jimi atropelados no trecho entre Garanhuns e Águas Belas da BR423.

Verifica-se, a partir da distribuição dos indivíduos nos mapas, que a área de maior frequência dos atropelamentos na BR 423 (Figura 5) ocorreram no município de Águas Belas, já bem próximo à entrada da cidade. Já para a BR 232 (Figura 6) a maior frequência foi na cidade de Pesqueira. Uma observação feita durante o período de coleta é que muitos desses atropelamentos ocorreram nas proximidades de corpos de água ou poças (Figura 7), permitindo sugerir que os atropelamentos desta espécie estão diretamente ligados 
também a proximidade com estes ambientes úmidos. Por mais que a espécie seja considerada terrestre enquanto adulta, a mesma depende destes ambientes tanto para facilitar na termorregulação, como para manutenção da sua reprodução e alimentação (OLIVEIRA et al., 2015). A partir desta distribuição, foram feitas relações entre as frequências de atropelamentos e os índices pluviométricos mensais do município (Figuras 8 e 9).

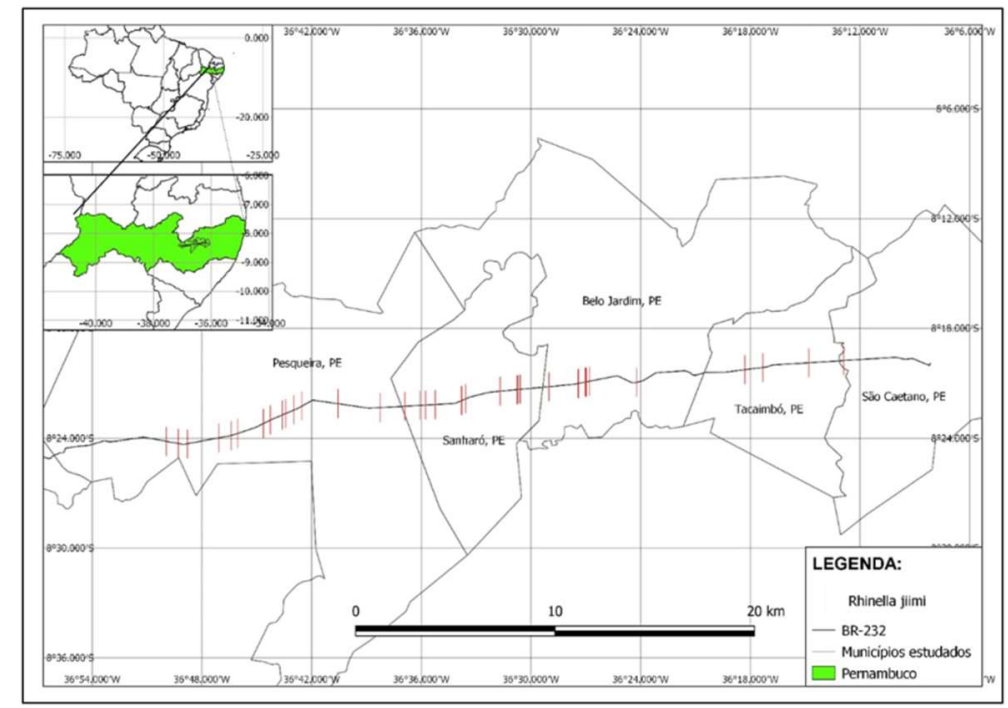

Figura 6: Distribuição espacial de indivíduos da espécie Rhinella jimi atropelados no trecho entre São Caetano e Arcoverde da BR232.

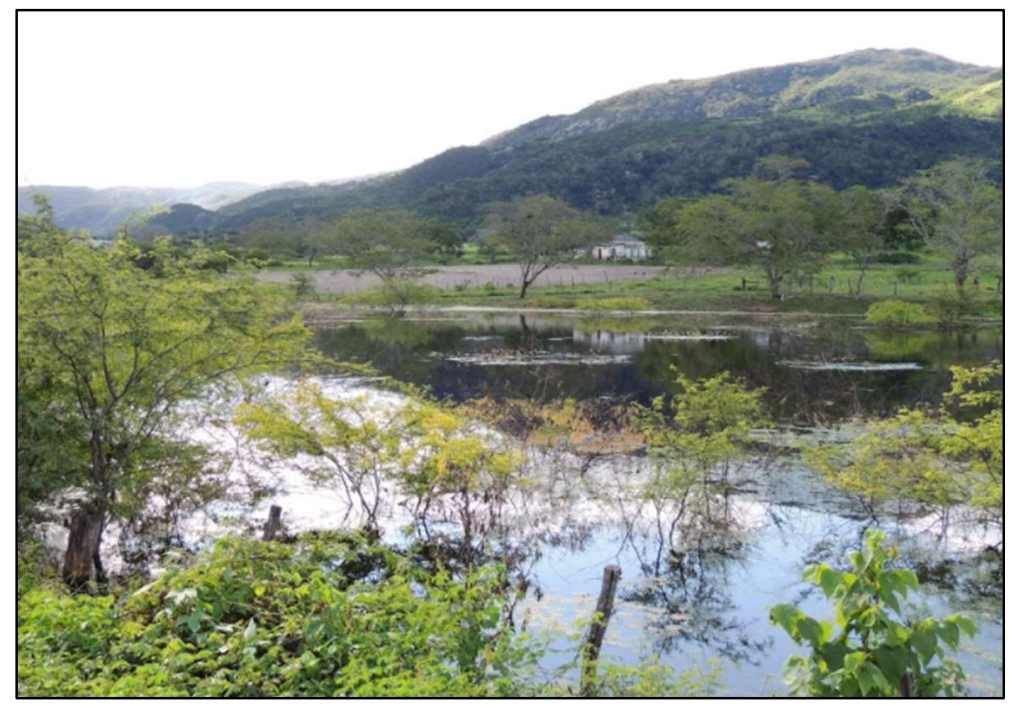

Figura 7: Corpo de água encontrado ao longo do trecho entre Garanhuns e Águas Belas da BR423.

Os índices de chuva na região da BR232 chegaram a números muito baixos nos primeiros seis meses de coleta e, consequentemente, baixos níveis de atropelamentos na região em estudo. A partir do mês de abril, os índices pluviométricos se elevam e pode-se observar um maior registro de atropelamentos da espécie R. jimi na rodovia (Figura 8). Tal motivo está diretamente ligado a adaptação da espécie no ambiente, já que neste período se concentram os maiores índices de chuvas na região (COLOMA et al., 2013). Aparentemente a espécie passou por um período de redução da atividade metabólica nos períodos mais secos e durante os períodos mais chuvosos retornou as suas atividades de reprodução/alimentação o que facilita os atropelamentos. Espécies do gênero Rhinella se deslocam para as regiões de maior umidade para reprodução e nutrição (COLOMA et al., 2013). Este fator garante que a espécie sua perpetuação e 
manutenção no habitat inserido.

Como os ovos precisam da água para o seu desenvolvimento e os níveis de evaporação na região semiárida são maiores que os de precipitação, é interessante para a espécie reproduzir-se em períodos onde a probabilidade dos ovos conseguirem eclodir e o girino se desenvolver seja maior, ou seja, na estação das chuvas. Essa estratégia reprodutiva para os anfíbios é conhecida como reprodução explosiva (BELL et al., 2010; SENARIS et al., 2014).

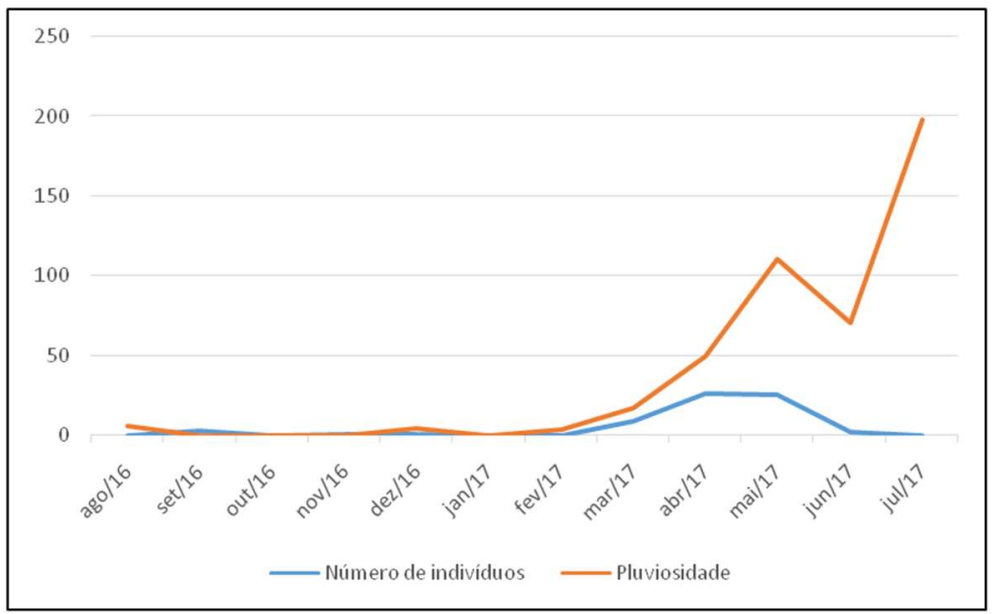

Figura 8: Relação da pluviosidade com o número de espécimes atropelados no município de Pesqueira no trecho da BR232.

No processo de reprodução explosiva, as espécies de anfíbios iniciam um processo de busca do lugar ideal para o amplexo, além de acelerar o seu processo metabólico (RASTOGI et al., 2011) necessitando neste processo da termorregulação já que se tratam de organismos ectotérmicos (ABRANTES et al., 2011). Outro aspecto é que a maior frequência dos atropelamentos ocorreu nas proximidades das zonas urbanas em ambas as rodovias e nestas, há maior luminosidade em função dos postes de iluminação, este fator é um atrativo para espécies de insetos e, consequentemente, para os anfíbios que se alimentam deles. Então, a luminosidade atrelada à disponibilidade de recursos alimentar, além da pluviometria que regula a distribuição destes dois grupos, está diretamente ligada ao maior número de atropelamentos de Rhinella jimi, interferindo sobremaneira na sua conservação.

O mesmo padrão de atropelamentos discutido no trecho da BR232 também foi observado na BR423 (Figura 9). Em agosto de 2017, março e abril de 2018, ocorreram os maiores índices pluviométricos, tendo os índices de atropelamentos também crescido em virtude do aumento de áreas úmidas e consequente aumento da atividade vital da espécie.

Outro dado importante de se analisar é que o mês de maior incidência de atropelamentos foi dezembro de 2017, quando os índices de pluviosidade do mês chegaram à $30 \mathrm{~mm}$. A relação para este fenômeno está diretamente ligada à reprodução da espécie, que ocorre nas chuvas, independentemente do mês. Durante o amplexo as fêmeas do gênero Rhinella podem depositar cerca de 5000 ovos na água com tempo médio de eclosão de dois dias (COLOMA et al., 2013). Desta forma, o aumento dos atropelamentos no mês de dezembro de 2017 é uma resposta secundária deste processo, já que as chuvas anteriores incitaram o processo de reprodução explosiva, fazendo com que a população de $R$. jimi naquele período 
tivesse um aumento significativo, e consequentemente, o surgimento de mais atropelamentos da espécie na região.

As espécies de anfíbios em geral, apresentam período de vida dualístico, passando por um processo de metamorfose. Enquanto jovem os indivíduos são adaptados ao ambiente aquático e se desenvolvem naquele ambiente, já na fase adulta, os anfíbios tornam-se mais adaptados ao ambiente terrestre, mas com dependência da umidade para sobreviver e reproduzir (HADDAD et al., 2013). O período de três meses entre as chuvas no município de Águas Belas e o ápice de atropelamentos dos espécimes pode estar vinculado ao processo de desenvolvimento dos espécimes no ambiente terrestre e consequente necessidade de nutrição e grande atividade metabólica. As ocorrências de atropelamentos se concentraram numa determinada região do fragmento de rodovia onde em suas margens encontram-se áreas alagadas durantes as chuvas, além de poças d'água ideais para a manutenção da espécie no ambiente.

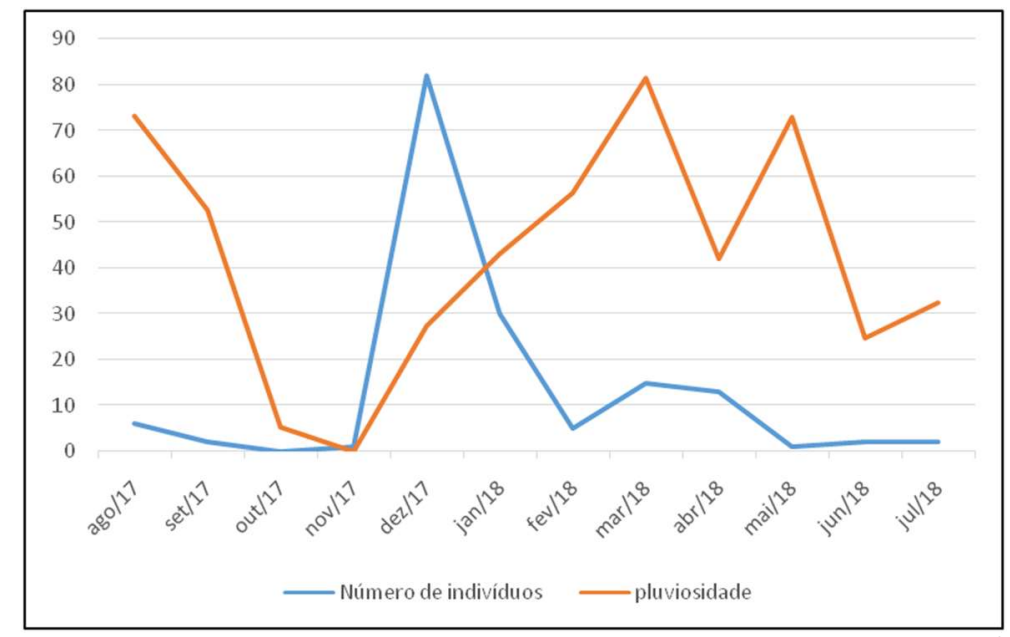

Figura 9: Relação da pluviosidade com o número de espécimes atropelados no município de Águas Belas no trecho da BR423.

Neste sentido, as espécies do gênero Rhinella são bastante adaptadas em ambientes antropizados (SILVA et al., 2016). A espécie $R$. jimi possui uma ótima adaptabilidade à região semiárida, assim como muitas espécies de anfíbios que povoam a região. Sendo assim, a climatologia da região delimita seu comportamento reprodutivo aos períodos chuvosos e às chuvas pontuais. Com o aumento das suas atividades de alimentação e reprodução durante os períodos de chuva, além da sua adaptação em ambientes antropizados, os espécimes desta espécie são comumente observados atropelados nestas rodovias, o que demonstra a relação existente entre essas atividades, os atropelamentos e a climatologia da região onde a espécie está inserida.

\section{CONCLUSÕES}

O quantitativo de espécimes atropelados de Rhinella jimi está diretamente relacionado com o período chuvoso no semiárido, uma vez que enquanto a população entra no período de reprodução, no início das chuvas, a população adulta cresce de forma significativa a procura de alimento e para ter maior eficiência na termorregulação, os espécimes acabam sendo atraídos pelas rodovias e consequentemente atropelados. 
As taxas de chuva elevam o número de indivíduos atropelados da espécie $R$. jimi tanto pelo fato de procura de alimento, quanto por sua maior atividade relativa ao início do ciclo reprodutivo da espécie.

O quantitativo de espécimes atropelados da espécie $R$. jimi pode estar associado à sua adaptação em ambientes antropizados e sua resistência à baixos índices de umidade na região do Semiárido.

Fatores como luminosidade, que aumentam o quantitativo de insetos, nas áreas urbanas, é um atrativo para tais anfíbios, assim como interações da própria ecologia do animal como territorialidade dos machos e atração das fêmeas pelo canto nas margens e poças próximas das rodovias, são possíveis casos a serem investigados em próximos trabalhos.

AGRADECIMENTOS: Ao setor de transportes da Universidade Federal Rural de Pernambuco - Unidade Acadêmica de Garanhuns pelo fornecimento do veículo durante todo o período de coleta de dados, Ao Laboratório de Ensino de Zoologia da Universidade Federal Rural de Pernambuco (LABEZoo-URFPE) pelo espaço de estudo e pesquisa oferecido e ao Programa de Pós-graduação em Ciências Ambientais (PPCIAM) pelo apoio acadêmico. Principalmente ao CNPq pelas bolsas de IC concedidas aos bolsistas (AML e DCSMMV) durante o desenvolvimento da pesquisa.

\section{REFERÊNCIAS}

ABRANTES, S. H. F.; ABRANTES, M. M. R.; OLIVEIRA, J. C. D.; OLIVEIRA, W. M.; HENRIQUES, I. G. N.; SILVA, P. F.; CHAVES, $M$. F.. Fauna de anfíbios anuros em três lagoas da área de implantação do Horto Florestal, campus da UFCG, CuitéPB. Revista Nordestina de Zoologia, v.5, n.2, p.19-36,2011.

ALVES, J. J.. Geoecologia da caatinga no semiárido do Nordeste brasileiro. CLIMEP-Climatologia e Estudos da Paisagem, v.2, n.1, 2007.

ANDRADE, S. P.; VAZ-SILVA, W.. First state record and distribution extension of Pleurodema diplolister (Peters 1870) (Anura: Leiuperidae) from state of Goiás, Brazil. Check List, v.8, n.1, p.149-151, 2012.

ANGELOTTI, F.; SIGNOR, D.; GIONGO, V.. Mudanças climáticas no Semiárido brasileiro: experiências e oportunidades para o desenvolvimento. In: EMBRAPA SEMIÁRIDO - ARTIGO EM PERIÓDICO INDEXADO (ALICE). Anais. 2015.

ASSIS, J. M. O.; SOUZA, W. M.; SOBRAL, M. C. M.. Climate analysis of the rainfall in the lower-middle stretch of the São Francisco River basin based on the rain anomaly index. Revista Brasileira de Ciências Ambientais, v.2, p.188202, 2015.

BAGER, A.; FONTOURA, V.. Evaluation of the effectiveness of a wildlife roadkill mitigation system in wetland habitat. Ecological Engineering, v.53, p.31-38, 2013.

BAGER, A.; PIEDRAS, S. R. N.; PEREIRA, T. S. M.; HOBUS, Q.. Fauna selvagem e atropelamento - diagnóstico do conhecimento científico brasileiro. Áreas Protegidas. Bager, A.. Repensando as escalas de atuação. Porto Alegre: Armazém Digital, 2007. p.49-62.
BARAT, J.. O investimento em transporte como fator de desenvolvimento regional-Uma análise da expansão rodoviária no Brasil. Revista Brasileira de Economia, v.23, n.3, p.25-52, 1969.

BELL, C. J.; GAUTHIER, J. A.; BEVER, G. S.. Covert biases, circularity, and apomorphies: a critical look at the North American Quaternary Herpetofaunal Stability Hypothesis. Quaternary International, v.217, n.1-2, p.30-36, 2010.

BELLARD, C.; BERTELSMEIER, C.; LEADLEY, P.; THUILLER, W.; COURCHAMP, F.. Impacts of climate change on the future of biodiversity. Ecology letters, v.15, n.4, p.365-377, 2012.

BERTUSSI, G. L.; ELLERY JUNIOR, R.. Infraestrutura de transporte e crescimento econômico no Brasil. Journal of Transport Literature, v.6, n.4, p.101-132, 2012.

BÖHM, M.; COLLEN, B.; BAILLIE, J. E.; BOWLES, P.; CHANSON, J.; COX, N.; RHODIN, A. G.. The conservation status of the world's reptiles. Biological Conservation, v.157, p.372-385, 2013.

COLOMA, L. A.; ORTIZ, D. A.; FRENKEL, C.; RON, S. R.. Rhinella marina. In: RON, S. R.; GUAYASAMIN, J. M.; YANEZMUÑOZ, M. H.; MERINO -VITERI, A.; ORTIZ, D. A.; NICOLALDE, D. A.. Amphibia Web Ecuador. Version 2014.0. Museo de Zoología, Pontificia Universidad Católica del Ecuador, 2013.

CUNHA, D. A.; COELHO, A. B.; FÉRES, J. G.. Irrigation as an adaptive strategy to climate change: an economic perspective on Brazilian agriculture. Environment and Development Economics, v.20, n.1, p.57-79, 2015. 
DELAZERI, L. M. M.; CUNHA, D. A.. Mudanças climáticas e migração rural-urbana no semiárido brasileiro. In: ENCONTRO NACIONAL DE ECONOMIA DA ANPEC, 43. Anais. 2015.

EAKIN, H. C.; LEMOS, M. C.; NELSON, D. R.. Differentiating capacities as a means to sustainable climate change adaptation. Global Environmental Change, v.27, p.1-8, 2014.

FERREIRA NETO, C. A.; CRUZ, G. A. S.; AMORIM, I. C.; BALBINO, V. Q.; MOURA, R. D. C.. Effects of fragmentation and anthropic pressure on the genetic structure of Canthon (Peltecanthon) staigi (Coleoptera: Scarabaeidae) populations in the Atlantic Forest domain. Journal of insect conservation, v.21, n.2, p.267-276, 2017.

FORMAN, R. T.; SPERLING, D.; BISSONETTE, J. A.; CLEVENGER, A. P.; CUTSHALL, C. D.; DALE, V. H.; JONES, J.. Road ecology: science and solutions. Island press, 2003.

FROST, D. R.. Amphibian species of the world: an online reference, version 5.4. 2010.

GUEDES, T. B.. Serpentes da Caatinga: diversidade, história natural, biogeografia e conservação. 2012.

GUTIÉRREZ, A. P. A.; ENGLE, N. L.; NYS, E.; MOLEJÓN, C.; MARTINS, E. S.. Drought preparedness in Brazil. Weather and Climate Extremes, v.3, p.95-106, 2014.

HADDAD, C. F.; TOLEDO, L. F.; PRADO, C. P.; LOEBMANN, D.; GASPARINI, J. L.; SAZIMA, I.. Guia dos anfíbios da Mata Atlântica: diversidade e biologia. Anolis Books, 2013.

HADDAD, N. M.; BRUDVIG, L. A.; CLOBERT, J.; DAVIES, K. F.; GONZALEZ, A.; HOLT, R. D.; COOK, W. M.. Habitat fragmentation and its lasting impact on Earth's ecosystems. Science advances, v.1, n.2, e1500052, 2015.

LIPINSKI, V. M.; SANTOS, T. G. D.. Structure and spatial organization of two anuran communities of the Pampa biome. Iheringia. Série Zoologia, v.104, n.4, p.462-469, 2014.

MARENGO, J. A.; CUNHA, A. P.; ALVES, L. M.. A seca de 201215 no semiárido do Nordeste do Brasil no contexto histórico. Revista Climanálise, v.3, p.49-54, 2016.

OLIVEIRA, J. C. D.; SOUSA, A. P. M.; CHAVES, M. F.; COSTA, D. F. S.; FERREIRA, L. L.. Hábito alimentar de Rhinella jimi, (Stevaux, 2002) (anura; bufonidea) no semiárido. Agropecuária Científica no Semiárido, v.10, n.4, p.19-25, 2015.

OLIVEIRA, R. F. D.; VIEIRA, L. D. R.; VIEIRA, A. G. T.. Anuros de uma área de Caatinga no Município de Caetés, Região Agreste do Estado de Pernambuco, Brasil. Revista Brasileira de Gestão Ambiental e Sustentabilidade, v.4, n.7, p.159165, 2017.

PEREIRA, T. C. S. D. O.. Ecologia trófica em uma taxocenose de anfíbios: estrutura, filogenia e especialização individual. Dissertação (Mestrado emBiodiversidade; Biologia Estrutural e Funcional) - Universidade Federal do Rio Grande do Norte, Natal, 2012.

PRADO, D. E.. As caatingas da América do Sul. Ecologia e conservação da Caatinga, v.2, p.3-74, 2003.

RAMOS-ABRANTES, M. M.; CARREIRO, A. D. N.; ARAÚJO, D. V.F.; SOUZA, J. G.; LIMA, J. P.R.; CEZAR, H. D. A.; ABRANTES, S. H. F.. Wild vertebrate's roadkill on the BR-230 highway, state of Paraíba, Brazil. PUBVET, v.12, n.1, p.1-7, 2018.

RASTOGI, R. K.; PINELLI, C.; POLESE, G.; D'ANIELLO, B.; CHIEFFI-BACCARI, G.. Hormones and reproductive cycles in Anuran Amphibians. In: HORMONES AND REPRODUCTION OF VERTEBRATES. Anais. Academic Press, 2011. p.171-186.

SANTOS, E. J.; CONTE, C. E.. Riqueza e distribuição temporal de anuros (Amphibia: Anura) em um fragmento de Floresta Ombrófila Mista. Iheringia. Série Zoologia, v.104, n.3, p.323333, 2014.

SEÑARIS, J. C.; LAMPO, M.; ROJAS-RUNJAIC, F. J.; BARRIOAMORÓS, C. L.. Guia ilustrada de los anfibios del Parque Nacional Canaima, Venezuela. Ediciones IVIC (Instituto Venozolano de Investigaciones científicas), 2014.

SILVA, F. R. S. D.. Sistemática e história natural de anfíbios anuros das nascentes dos rios Samã e Miang em áreas de altitude do Escudo da Guiana em Roraima (Amphibia, Anura). 2016.

TROMBULAK, S. C.; FRISSELL, C. A.. Review of ecological effects of roads on terrestrial and aquatic communities. Conservation biology, v.14, n.1, p.18-30, 2000 .

VIEIRA, W. L. S.; ARZABE, C.; SANTANA, G. G.. Composição e distribuição espaço-temporal de anuros no Cariri paraibano, Nordeste do Brasil. Oecologia Brasiliensis, v.11, n.3, p.383396, 2007.

A CBPC - Companhia Brasileira de Produção Científica (CNPJ: 11.221.422/0001-03) detém os direitos materiais desta publicação. Os direitos referem-se à publicação do trabalho em qualquer parte do mundo incluindo os direitos às renovações, expansões e disseminacões da contribuicão, bem como outros direitos subsidiários. Todos os trabalhos publicados eletronicamente poderão posteriormente ser publicados em coletâneas impressas sob coordenação da Sustenere Publishing, da Companhia Brasileira de Produção Científica e seus parceiros autorizados. Os (as) autores (as) preservam os direitos autorais, mas não têm permissão para a publicação da contribuição em outro meio, impresso ou digital, em português ou em tradução. 